\title{
Optimal Control with an Interval-valued Objective Function: an Application in Weed Management
}

\section{Ulcilea A. Severino Leal ${ }^{1}$}

Universidade Federal de Mato Grosso do Sul, UFMS, Chapadão do Sul, MS

Elenice W. Stiegelmeier ${ }^{2}$

Department of Mathematics, UTFPR, Cornélio Procópio, PR

Geraldo N. Silva ${ }^{3}$

Department of Applied Mathematics, UNESP-IBILCE, São José do Rio Preto, SP

Weldon A. Lodwick ${ }^{4}$

Department of Mathematics and Statistical Sciences, UCDenver, Denver, USA

\begin{abstract}
This paper investigates how optimal controle can support weed management by looking specifically at an optimal control problem with an interval-valued objective function based on dynamic optimization. The dynamic optimization problem involves continuous variables modeled as an interval-valued nonlinear programming (INLP) problem. In this study, we converted the INLP problem into into a multi-objective problem using the concept of order relation and solver the multi-objetive problem using the weight method. We solved the resultant NLP problem with an active-set algorithm (ASA) for box-constrained optimization. Finally, we carried out an application in a weed management problem.
\end{abstract}

Keywords. Optimal control, interval-valued function, application, weed management.

\section{Introduction}

This paper investigates an optimal control problem with and interval-valued objective function and, in particular, looks at how optimal control can support weed management and infestation control in a wide range of problems found in agriculture today. The relevance of optimizing resources in agriculture is undeniable. Weed management avoids losses due to competition in order to benefit crop conditions, avoid further infestation, and protect the environment. Today, the main method of weed control is the use of herbicide.

Weeds grow naturally in agricultural soils, creating high competition among resources that are necessary for crop growth. The competition between weeds and crop plants

\footnotetext{
${ }^{1}$ ulcilea.leal@ufms.br

${ }^{2}$ elenicew@utfpr.edu.br

${ }^{3}$ gsilva@ibilce.unesp.br

${ }^{4}$ Weldon.Lodwick@ucdenver.edu
} 
occurs when two or more plants use or remove resources that are limited in a common ecosystem, but essential for plant growth and development. In other words, plants inhibit other plants by limiting resources consumption. For this reason, we need weed control strategies that maximize the productivity of a crop. This profit function depends on the price of the crop, on the cost of weed control, and on the other factors that influence production. Because, these parameters are not deterministic, we consider them intervalvalued. Therefore, another objective is to describe the possible scenarios of the profit.

Researchers have used optimization strategies in several weed management programs $[5,6,8,9]$ to describe variations of the profit and used dynamic programming techniques to find optimal strategies. In one study, Jones and Cacho [5] and Jones et al. [6] obtained an optimal level of weed control that maximized economic benefits in terms of a single herbicide dose sequence. They used the Pontryagin Maximum Principle and dynamic programming to solve the optimal control problem in question. Kotani el al. [8] and Kotani el al. [9] also used a dynamic model of weed management and proposed an optimal decision rule for weed removal, including whether or not to eradicate them.

\section{An application in weed management}

The weed dynamics considered in this paper are the weed seed bank and seedling densities. Let $x_{t}$ denote the weed seed bank [5], $y_{t}$ the seedling densities [5], and $t$ the production cycle. The weed population model have the following form:

$$
\begin{aligned}
y_{t} & =x^{g} \delta x_{t}, x_{t_{0}}=x_{0} \\
y_{t}^{a} & =\left(1-\rho\left(u_{t}\right)\right) y_{t} \\
x_{t}^{r} & =\exp \left[\gamma \ln y_{t}^{a} /\left(\mu+\varepsilon \ln y_{t}^{a}\right)\right] \\
x_{t}^{n} & =\kappa x_{t}^{r}-\eta+\xi \\
x_{t+1} & =x_{t}^{n}+(1-\Psi)(1-\delta) x_{t},
\end{aligned}
$$

where $x_{t}$ is the weed seed bank density at the beginning of cycle $t\left(m^{-2}\right), y_{t}$ is the seedling in cycle $t\left(m^{-2}\right), y_{t}^{a}$ is the density of the mature plants $\left(m^{-2}\right), x_{t}^{r}$ is the seeds resulting from the reproduction of weeds $\left(m^{-2}\right), x_{t}^{n}$ is the new seeds added to the seed bank $\left(m^{-2}\right), x^{g}$ represents the proportion of germination, $\delta$ is the annual germination rate of the weed seed, $u_{t}$ is the dose of herbicide (liter $h a^{-1}$ ), $\rho$ is the herbicide-induced mortality of seedlings, $\gamma, \mu, \varepsilon$ are the regression coefficients given by [11], $\kappa$ is the survival rate of new seeds, $\eta$ is the seeds export such as removal of seeds at harvest $\left(\mathrm{m}^{-2}\right), \xi$ is the import of seeds $\left(\mathrm{m}^{-2}\right)$, and $\Psi$ is the death rate of dormant seeds. Using the equations (1) - (5), the dynamic model for the seed bank density of weeds for applied herbicide is written in terms of the function $g$ as

$$
x_{t+1}=g\left(x_{t}, u_{t}\right)
$$

where

$$
g\left(x_{t}, u_{t}\right)=(1-\Psi)(1-\delta) x_{t}+\kappa \exp \left(\frac{\gamma \ln \left(\left(1-\rho\left(u_{t}\right)\right) x^{g} \delta x_{t}\right)}{\mu+\varepsilon \ln \left(\left(1-\rho\left(u_{t}\right)\right) x^{g} \delta x_{t}\right)}\right)-\eta+\xi .
$$


Therefore, the dynamic of the weed seed bank is given in (6), in which $\rho$ describes the herbicide-induced mortality of seedlings in cycle $t$ where the control variable is described by $u_{t}$ and determined by the weed-management strategy employed during each iteration.

The logistic model to be fitted to the survival data is as follows [13]:

$$
\rho(u)=c+\frac{d-c}{1+\exp \left[b\left(\ln (u)-\ln \left(G R_{50}\right)\right)\right]},
$$

where $\rho$ is plant survival as a percentage, $c$ is the lower asymptotic values of $\rho$, and $\mathrm{d}$ is the upper asymptotic values of $\rho$. The parameter $G R_{50}$ is the herbicide rate which produces a survival level halfway between the lower limit zero and upper limit $d$. The parameter $u$ is the herbicide dose, and the parameter $b$ denotes the relative slope around $G R_{50}$. We used the fitted logistics model to estimate the rate of herbicide that causes $50 \%$ grow reduction $\left(G R_{50}\right)$, and the parameters $b, c, d$ and $G R_{50}$ were determined experimentally.

The seed bank can be indirectly regulated by changing weed control inputs that target the mortality or vigor of plants (eg. cultivation, herbicides) or through losses via seed mortality (eg. cultivation, stubble burning, seed predation).

\section{Formulation of interval-valued optimization problem}

The purpose of the weed optimal control problem is to evaluate changes in the weed density of the crop based on the application of herbicides. We did not use any technical control other then the chemical defense application. As such, the economic problem is considered as variables: the initial population of weeds, $x_{t}$ and herbicide dose applied, $u_{t}$, and all other factors will be fixed, as made by [5]. For simplicity of exposition assume that the only form of weed control is from the application of a herbicide. Following [5], the profit function for a optimal herbicide dose problem is define as

$$
\pi\left(x_{t}, u_{t}\right)=P_{y} Y\left(x_{t}, u_{t}\right)-P_{u} u_{t}-C,
$$

where $P_{y}$ is the crop price, $P_{u}$ is the cost per unit cost of weed control, $C$ is the constant application cost for the weed control input, and represents the remaining production factors. These coefficients have some variations that we will consider with interval coefficients. The first term of the equation $P_{y} Y\left(x_{t}, u_{t}\right)$ represents the total revenue and is determined not only by the level of the control variable but also by the initial weed density $x$. Thus, the total revenue for any variation in $u_{t}$ will be specific to the initial value of $x_{t}$. The function $Y\left(x_{t}, u_{t}\right)$ represents the crop yield described by [5]: $Y=Y_{0}\left(1-Y_{L}\right)\left(1-Y_{p}\right)$, where $Y_{0}$ is the weed-free yield, $Y_{L}$ is the yield loss associated with the weed density and the weed control, and $Y_{p}$ is the yield loss associated to the phytotoxic effects of herbicide.

The appropriate loss function that describes yield loss as a function of weed density is a rectangular hyperbola function [1]: $Y_{L}=\frac{a D}{1+\frac{a}{m} D}$, where $a$ is percentage of yield loss per unit weed density $\left(\mathrm{m}^{-2}\right), m$ is an estimate of the maximum yield loss of a weed crop relative to the yield of a weed-free crop, and $D$ is a function of initial weed density and the rate of weeds killed by the herbicide dose $\rho\left(u_{t}\right): D=y_{t}(1-\rho), \quad 0 \leq \rho \leq 1$. Here, $\rho$ acts as a dose response function given by a logistic model [13]. We estimated the yield loss 
associated with the phytotoxic effects of herbicide as [12]: $Y_{p}=\varphi u_{t}$, where $\varphi$ represents an adjusted parameter that depends on the applied herbicide.

In a dynamic setting, the objective of a farmer is to determine the level of depletion in the stock of the seed resource $\left(x_{t}\right)$ the has resulted from herbicide application $\left(u_{t}\right)$ in each cycle $t$ that maximizes profit over a period of $T$ cycles.

The profit function we present depends on the crop price, of the cost of weed control, and of the remaining production factors. However, these parameters are not deterministic, so we consider them interval-valued. Considering this, we have reformulated the profit function (8) to consider the interval-valued problem. It is given by

$$
\Pi\left(x_{t}, u_{t}\right)=\left[\underline{P_{y}}, \overline{P_{y}}\right] Y\left(x_{t}, u_{t}\right)-\left[\underline{P_{u}}, \overline{P_{u}}\right] u_{t}-[\underline{C(t)}, \overline{C(t)}]
$$

where $\left[P_{y}, \overline{P_{y}}\right] Y$ represents the total revenue and is determined not only by the level of the control variable and the initial weed density $x$ but also by the uncertain crop price. Furthermore, the interval-valued profit function considers uncertainty in both the cost of weed control, $\left[\underline{P_{u}}, \overline{P_{u}}\right]$, and the cost of the remaining production factors, $[C(t), \overline{C(t)}]$. In this form, the interval-valued optimization problem for weed control is proposed by

$$
\max J=\sum_{t=0}^{T} \alpha^{t} \Pi\left(x_{t}, u_{t}\right)
$$

subject to:

$$
\begin{aligned}
& x_{t+1}=g\left(x_{t}, u_{t}\right) \\
& x(0)=x_{0} \\
& 0 \leq u(t) \leq u_{\max }
\end{aligned}
$$

where $J$ is the interval-valued profit in time $T, \Pi$ is the E-differentiable given by (9), $\alpha^{t} \in(0,1)$ the discount rate [7], and $u_{\max }$ the highest dose of herbicide allowed in the field and (13) $u_{t}$ is box-constrained.

Because the optimization problem (10)-(13) has an interval-valued objective function, we adopted a strategy to convert it into a bi-objective optimization problem, as described in [10]. The resultant bi-objective problem can be solved by classic methods that transform a multi-objective problem into a mono-objective one. Here, we used the weight method. Since the control variable $u_{t}$ is box-constrained, it was necessary to use a box-constrained method. Therefore, we decided to use the ASA method proposed by Hager and Zhang [2] available at [3] is used. The solution of the corresponding problem yields the optimal control strategy.

\section{Results and discussion}

In this section, we present a case study where one herbicide was applied to Bidens subalternans in a corn crop. We had an initial seed bank of 500 (seeds $m^{-2}$ ), and in the simulation we used one herbicide (atrazine) for postemergent (foliage-absorbed) control of the weed population. The weed control problem was simulated over a 10-year period, 
Tabela 1: Parameter values used in the numeric simulation

\begin{tabular}{lc}
\hline Population parameters & Value \\
\hline$\delta(\%)$ & 60 \\
$\psi(\%)$ & 30 \\
$\eta\left(m^{-2}\right)$ & 0 \\
$\xi\left(m^{-2}\right)$ & 0 \\
$\kappa(\%)$ & 30 \\
$x^{g}(\%)$ & 60 \\
$\gamma$ & 6,80 \\
$\mu$ & 2,00 \\
$\varepsilon$ & 0,67 \\
\hline Dose responde parameters & \\
\hline $\mathrm{b}$ & $-0,18$ \\
$\mathrm{c}$ & $-3,05$ \\
$\mathrm{~d}$ & 103,04 \\
$G R_{50}\left(\right.$ liter $\left.h a^{-1}\right)$ & 727,33 \\
\hline Economic parameters & \\
\hline$\left[P_{y}, \overline{P_{y}}\right]\left(\mathrm{R} \$\right.$ ton $\left.^{-1}\right)$ & {$[498 ; 547,8]$} \\
{$\left[\underline{P_{u}}, \overline{P_{u}}\right]\left(\mathrm{R} \$\right.$ liter $\left.^{-1}\right)$} & {$[11,90 ; 12,90]$} \\
$\overline{Y_{0}}\left(\right.$ ton $\left.h a^{-1}\right)$ & 7,80 \\
{$[\underline{C}, \bar{C}]\left(\mathrm{R} \$ h^{-1}\right)$} & {$[954,73 ; 1457,09]$} \\
$u_{m a x}($ liter ha \\
\hline
\end{tabular}

and the parameter values of the population and economic models used in the annual corn harvest system 2013/2014 [4] are shown in Table 1.

Figura 1: Optimization result for a 10-year simulation.

Figure 1(a) shows the optimal seed bank dynamics, $\widehat{x}$, and Figure 1(b) illustrates the optimal control, $\widehat{u}$, for a 10-year simulation. We controlled the weed population was controlled for the herbicide applied (see Figure 1(a)). Figure 1(b) illustrates the decrease in herbicide doses given by the optimal control strategy for the herbicide. This decrease in herbicide doses is important to reduce the environmental impact caused by the excessive use of herbicides.

Figure 1(c) shows the simulation scenario for the optimistic and pessimistic net present value of the weed management problem. The lower curve represents the worst-case scenario and the upper curve the best-case scenario for the profit as reflected in the profit changes based on changes in production cost and the and the price of each unit of control. Figure $1(\mathrm{~d})$ illustrates the scenario of net present value for the 10-year simulation in both upper and lower bounds.

Therefore, the decision support system based on optimal control that considers intervalvalued function of this study takes into account important requirements arising in agri- 
culture resources management with regards to weed population dynamics and control.

\section{Conclusions}

In this study, we discussed optimal weed control to support agriculture resources management and control and established a dynamic optimization model to consider intervalvalued function. We proposed a single herbicide sequence to control weed infestation by maximizing economic returns. The results are promising as they indicate that decreased herbicide doses are economically viable to single herbicide sequences due to the seed bank is controlled. In addition, the presented model is useful to explain the change in the profit over time and to demonstrate that the optimal control problem with interval-valued objective function in a population plays an important role in weed management.

\section{Acknowledgments}

The research in this work has been partially supported by both FAPESP-Brazil under the grants (2012/00189 - 3 and CEPID 2013/07375 - 0 of Industrial Mathematics) and CNPq under the grants (309335/2012 - 4 and 479109/2013 - 3) and Capes Foundation under the grant (BEX 11153/13-0).

\section{Referências}

[1] R. Cousens, A simple model relating yield loss to weed density, Annals of Applied Biology, 107 (2), 239-252, (1985).

[2] W. W. Hager, H. Zhang, A new active set algorithm for box constrained optimization, Journal of Optimization, 17 (2), 526-557, (2006).

[3] W. Hager, Source code for ASA-CG version 1.3, Available at:

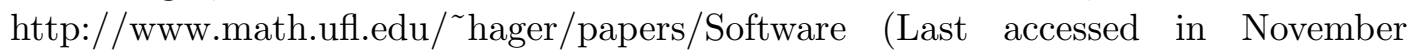
2009).

[4] Instituto Mato-Grossense de Economia Agrapecuária (IMEA), Custo de produção de milho - Safra 2013/14, Available at: http://www.imea.com.br/upload/publicacoes/ arquivos/ R410-2013-01-CPMilho.pdf (Last accessed in January 2015).

[5] R. Jones, O. J. Cacho, A dynamic optimization model of weed control, in: 44th Annual Conference of the Australian Agricultural and Resource Economics, Sydney, Australia, 1-17, (2000).

[6] R. Jones, O. J. Cacho, J. Sinden, The importance of seasonal variability and tactical responses to risk on estimating the economic benefits of integrated weed management, Agricultural Economics, 35 (3), 245-256, (2006). 
[7] J. O. S. Kennedy, Dynamic Programming: Applications to Agriculture and Natural Resources, Elsevier, New York, NY, (1986).

[8] K. Kotani, M. Kakinaka, H. Matsuda, Dynamic economic analysis on invasive species management: Some policy implications of catchability, Mathematical Biosciences, 220 (1), 1-14, (2009).

[9] K. Kotani, M. Kakinaka, H. Matsuda, Optimal invasive species management under multiple uncertainties, Mathematical Biosciences, 233 (1), 32-46, (2011).

[10] U. A. S. Leal, G. N. Silva, W. A. Lodwick, Multi-objective optimization in optimal control problem with interval-valued objective function, Proceeding Series of the Brazilian Society of Computational and Applied Mathematics, Vol.1, (2014).

[11] R. Medd, H. I. Nicol, A. Cook, Seed kill and its role in weed management system: A case study of seed production, seed banks and population growth of avena species (wild oats), in: Ninth European Weed Research Society Symposium, Vol. 2, Budapest, 627-632, (1995).

[12] S. Pandey, R. Medd, Integration of seed and plant kill tactics for control of wild oats: An economic evaluation, Agricultural Systems, 34 (1), 65-76, (1990).

[13] S. S. Seefeldt, J. E. Jensen, E. P. Fuerst, Log-logistic analysis of herbicide doseresponse relationships, Weed Technology, 9 (1), 218-227, (1995). 